\title{
Resource Allocation Mechanism of Students' Political Education in Major Universities in China
}

\author{
Xuejun Zhang a, ${ }^{\star}$ \\ Rizhao Polytechnic, China \\ *,a173042796@qq.com
}

\begin{abstract}
Keywords: allocation of ideological and political education resources; index system; BP neural network.
\end{abstract}

\begin{abstract}
To explore students' political education in major universities in China, starting with the actual situation of the allocation of ideological and political education resources in colleges and universities, combined with relevant theories, the allocation evaluation index system of ideological and political education resources in colleges and universities was established based on the in-depth analysis of the purpose, content and principles of the evaluation system for the allocation of resources in ideological and political education in colleges and universities. The evaluation index system covered specific indexes such as the average area of student housing, the number of books owned by students, the number of computers per student, the ratio of teachers and students and so on. The BP neural network was selected as the main evaluation method for constructing the resource allocation evaluation system of ideological and political education in colleges and universities. The analysis and processing of the input layer variables in the concrete construction of the BP network model were set up, and the practice process of the resource allocation evaluation system of the ideological and political education in the BP neural network was studied. Specifically, in the MATLABR2012a software environment, through the concrete data of the allocation of resources in the ideological and political education of colleges and universities and the extended data obtained by using the interpolation method, the BP neural network system was constructed and the simulation training was carried out. The evaluation results are basically consistent with the expected results, which indicate the operability and practicability of the resource allocation evaluation system of ideological and political education in colleges and universities.
\end{abstract}

\section{Introduction}

Colleges, as a part of society, are the same as other organizations. The ideological and political education discipline, like other disciplines, will be affected by the information age. The subject of ideological and political education, as a subject of shaping values, has shown some new changes in the face of massive information shock. First of all, because of the development of the network and the growing rich form of media, the number of information that college students face and receive every day is huge. Whether it is active receiving or passive or unaware, the culture of the network imperceptibly affects their thoughts slowly towards pluralism. However, the influence is both positive and negative, and what is worth noting is that as the updating of the information is speeding up, the students' thought is also speeding up. However, the university stage is the key period for the formation of the values of the students' outlook on life, which increases the pressure for the ideological and political education of colleges and universities [1].

The history of ideological and political education is relatively short, so the theoretical research on ideological and political education in colleges and universities is relatively few. The research on the allocation of educational resources is still relatively inadequate, and there is little research on how to optimize and integrate the educational resources of ideological and political education in the era of big data [2]. This article will make a systematic analysis of the relevant concepts, problems, causes and solutions of the current ideological and political education resources allocation in colleges and 
universities. The discussion and research expects to make efforts for the development of the ideological and political education in the era of big data.

\section{Literature Review}

In 1970s, with the development of society, many countries in the world paid more and more attention to education, so they began to define, measure, and evaluate the quality of education. Jonathan T Hughes put forward a set of theory of resource sharing through the practical experience of educational resources sharing research in the United States. It provides a new research idea for how to integrate the limited educational resources and achieve the highest utilization rate, thus providing a new research idea for realizing the balanced rationalization of educational resources [3]. John Rols, the political philosopher of the United States, put forward the famous "principle of compensation", which holds that all people have equal opportunities for equal social status, and should make some compensation for their own births and innate qualifications, so that the resources can be tilted to a certain extent. We should pay attention to the compensation and assistance for vulnerable groups, and lay stress on the tilt of resource allocation, so as to achieve equality and fairness in education [4]. In Zhang Rui's Creative Exploration of Ideological and Political Education in Colleges and Universities in the Era of Big Data, it is believed that the enhancement of the awareness of data is the guarantee for the continued development of ideological and political education in colleges and universities. The main body of ideological and political education should enhance the awareness and sensitivity of data and the ability to organize and process information [5].

\section{Design of Evaluation System for Compulsory Education Resource Allocation Based on BP Neural Network}

Artificial neural network (ANN) is the result of neural network simulation obtained on the basis of neural network simulation, which is the same as the basic constitution of the biological neural network and is composed of a series of neurons and corresponding connections. Therefore, although the artificial neural network has many structures, the most basic processing unit is artificial neuron [6]. A neuron $\mathrm{k}$ can be used expressed by the following formula:

$$
\begin{aligned}
& u_{k}=\sum_{i=1}^{m} w_{i k} x_{i} \\
& y_{k}=f\left(u_{k}+b_{k}\right)
\end{aligned}
$$

In MATLAB, the learning samples we collect are input in the model in the form of matrix. The different physical meaning of the selected indexes in the evaluation system, and the magnitude of each vector is different, so the data are usually normalized firstly, and the data are converted to [0,1] or $[-1,1]$. Through the normalization of data, the network learning error caused by the big difference of input data is larger, which is beneficial to improve the speed of network training and accelerate the convergence. The maximum and minimum method is applied to the data processing in the algorithm, and the formula is as follows [7]:

$$
x=\frac{x-x_{\min }}{x_{\max }-x_{\min }}
$$

The BP neural network model constructed in this paper determines the best training algorithm through experiments. The first level is the input layer, and the input variable is the evaluation index of compulsory education resource allocation. The middle layer is the hidden layer. By adjusting the weights of neurons, the actual sample obtained is close to the target sample of the evaluation of university students' political education resources allocation. The last layer is output layer, which outputs the result data, and network output can be adjusted accordingly to get the evaluation result. The specific training flow chart of the evaluation system of university students' political education resources allocation is shown in Figure 1. 


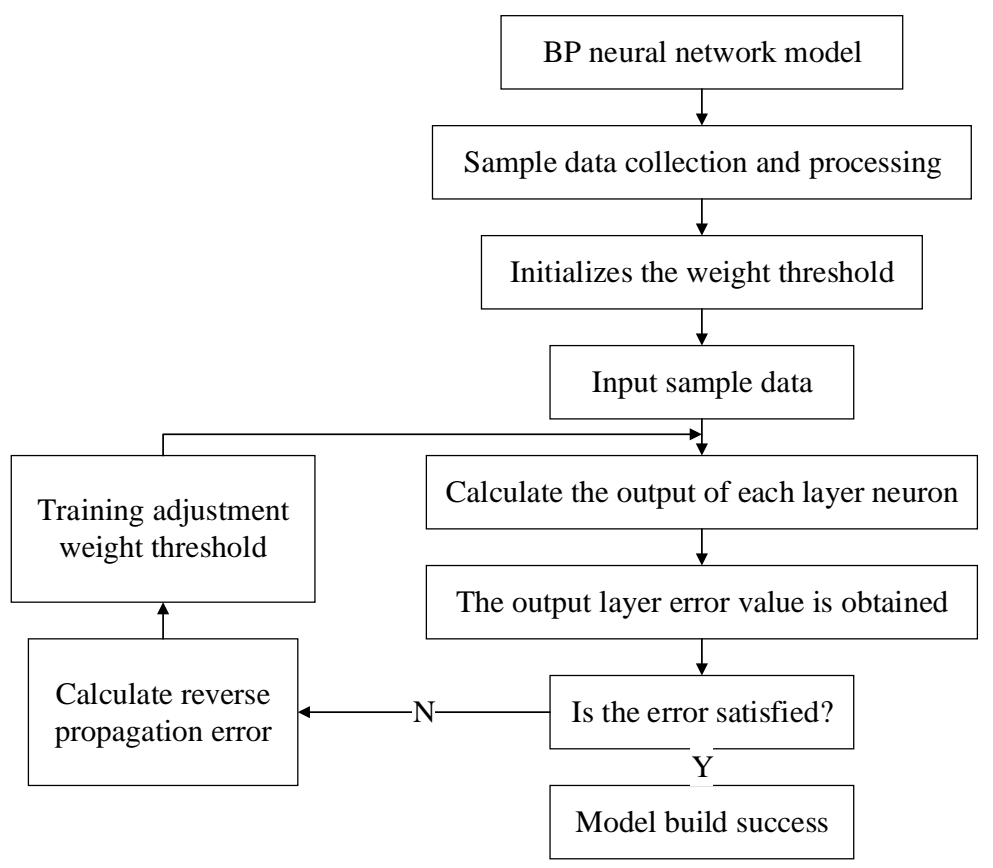

Figure. 1 The flow chart of the evaluation system of university students' political education resources allocation

\section{Simulation of Compulsory Education Resource Allocation Evaluation System Based on BP Neural Network}

\subsection{Selection of Evaluation Criteria and Evaluation Indexes}

The key point of building the system with BP neural network is to train the network repeatedly with a large number of typical related data, strengthen the learning and understanding of the network on the research problems, and make the network finally trained more accurate. We adjust the corresponding function or training parameter according to the problems occurred in the network training process [8]. Finally, a comprehensive BP evaluation system for university students' political education resources allocation is formed, so that it can be applied to practical problems. The evaluation criteria adopted in this practice study are shown in Table 1.

Table 1 Evaluation grade classification table

\begin{tabular}{|c|c|c|c|c|}
\hline Levels & v & g & a & b \\
\hline Content & Very good & Good & Acceptable & Poor \\
\hline Expected output & {$[1,0,0,0]$} & {$[0,1,0,0]$} & {$[0,0,1,0]$} & {$[0,0,0,1]$} \\
\hline
\end{tabular}

4.2 Establishment of An Evaluation Network Model for University Students' Political Education Resources Allocation

In order to avoid the poor performance of the network, not ideal evaluation results and so on problems and to improve the network precision, this paper uses the interpolation method in MATLAB to expand the 10 sets of data of the training samples, and then generates 20 sets of training samples, and the same method is used to determine the expected output. The evaluation of university students' political education resources allocation BP network model test sample is shown in Table 2.

Table 2 Evaluation of university students' political education resources allocation BP network model

test sample

\begin{tabular}{|c|c|c|c|c|}
\hline $\begin{array}{c}\text { Sample } \\
\text { number }\end{array}$ & $\begin{array}{c}\text { Average schoolhouse } \\
\text { area }\left(\mathrm{m}^{2}\right)\end{array}$ & $\begin{array}{c}\text { The average amount of book } \\
\text { ownership (piece) }\end{array}$ & $\begin{array}{c}\text { Average computer } \\
\text { number (piece) }\end{array}$ & $\begin{array}{c}\text { Ratio of teachers and } \\
\text { students }(\%)\end{array}$ \\
\hline 1 & 9.701465 & 20.17683 & 0.081752 & 0.081381 \\
\hline 2 & 8.567652 & 24.23847 & 0.106558 & 0.066148 \\
\hline 3 & 7.297547 & 16.82556 & 0.058768 & 0.059567 \\
\hline 4 & 6.906551 & 18.02385 & 0.045097 & 0.056916 \\
\hline
\end{tabular}

We determine the structure of BP network model suitable for the evaluation system of college students' political education resources allocation and the setting and value of relevant program 
parameters in the process of training and operation. The training function and training parameters are shown in Table 3.

Table 3 Network training parameter table of university students' political education resource allocation evaluation system

\begin{tabular}{|c|c|c|c|c|c|}
\hline Name & Value & Name & Value & Name & Value \\
\hline Network structure & $8-17-4$ & Maximum number of iterations & 1000 & Target accuracy & 0.0001 \\
\hline Training function & traingdx & Training sample number & 30 & Display step length & 200 \\
\hline Learning speed & 0.03 & Activation function & tansig and purelin & & \\
\hline
\end{tabular}

The BP neural network model can be used to train the university students' political education resource allocation evaluation by replacing the sample data under the MATLABR2012a environment and running the corresponding code statements of the MATLAB. The specific training interface and training results of the network are shown in Figures 2 and 3.

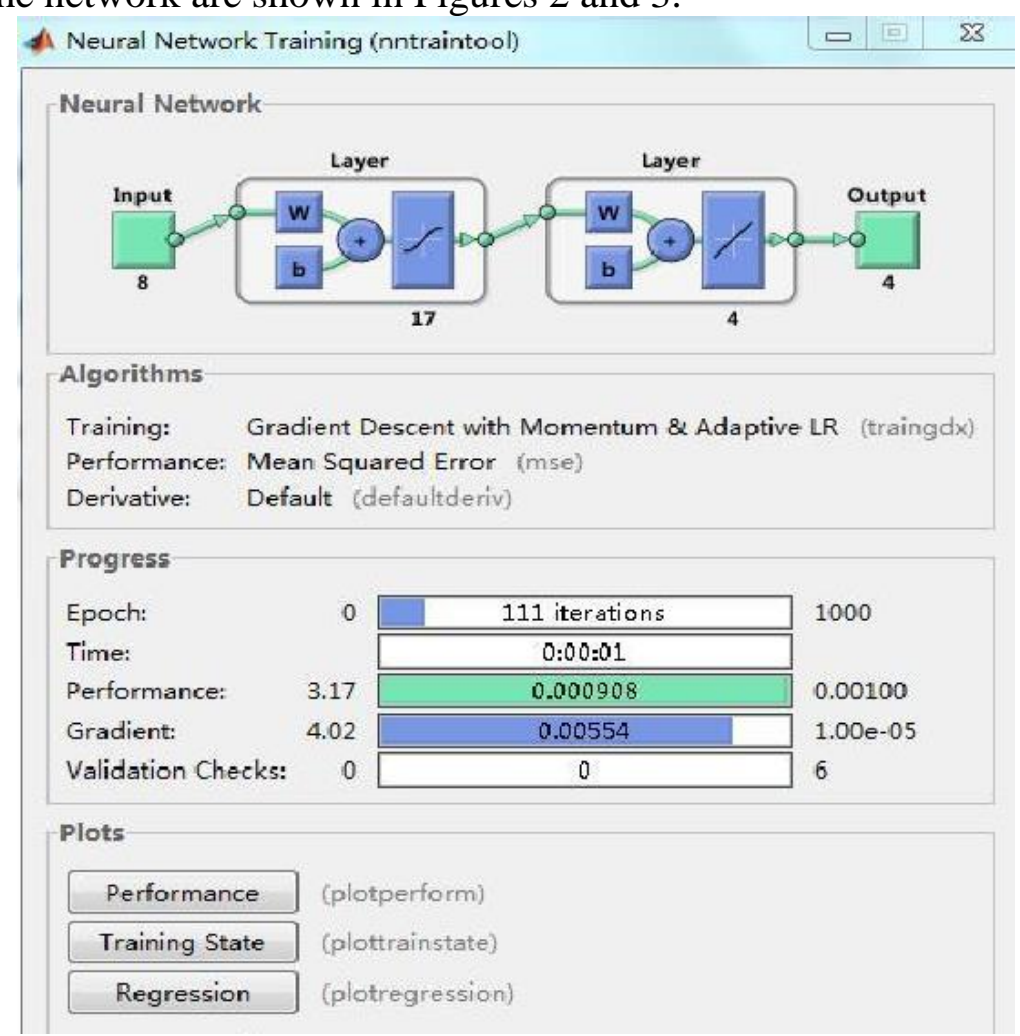

Figure. 2 Evaluation of university students' political education resources allocation BP neural network training interface

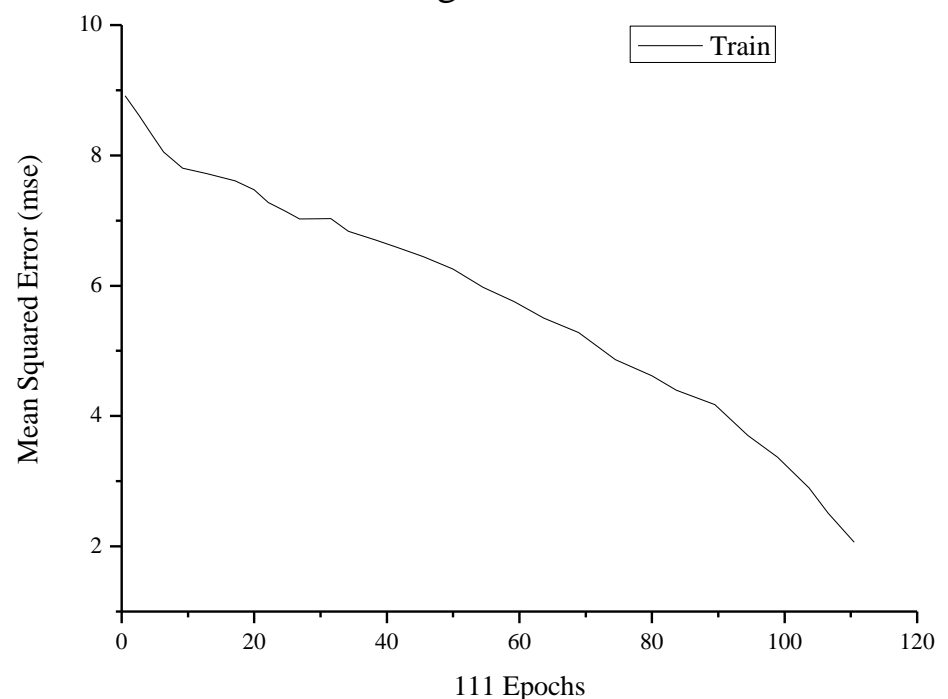

Figure. 3 Training results of university students' political education resources allocation BP neural network training interface 


\subsection{Analysis of Evaluation Results}

According to the simulation results of training samples and test samples above, it can be seen that whether the actual output values and expected output errors of the training samples or the actual output values of the tested samples and the expected output error values are relatively small. As a result, the trained network can be applied to the evaluation of allocation of compulsory education resources. Therefore, it also proves the feasibility of applying BP neural network to the administrative management of compulsory education resource allocation evaluation.

There are many kinds of resources for ideological and political education in colleges and universities, and the internal allocation of resources is, first, the allocation of thematic resources. Because of the different specialties of different educators, some human strength and endurance are very strong, and some people have rich brain and experience. Everyone has their own strengths, so in the process of ideological and political education in colleges and universities, they are assigned to different posts and play the role of different positions according to the differences of individual quality and ability. This different division of labor can not only mobilize the enthusiasm of the various subjects, but also promote the efficiency of the function of the allocation of thematic resources. Secondly, it is the internal configuration of cultural resources. Taking the campus culture as an example, the internal configuration of cultural resources is firstly its own three levels, namely, the allocation of the system layer, material layer and spiritual layer. In the process of the allocation of the system layer, material layer and spirit layer, the spirit layer is the core of the campus culture; and the system layer is the middle level of the campus culture that embodies the demands of the educator. Thirdly, it is the configuration of the internal resources of the carrier. With the popularization of the network, many universities have fully realized the significance of the network to the ideological and political education of colleges and universities. At the same time, we should strengthen the construction of the campus website and develop the resources of the campus website as much as possible.

\section{Conclusion}

This paper tries to study the problem of the allocation of resources in ideological and political education in colleges and universities, trying to solve the problem of insufficient supply of material resources, spare part of the resources, and serious waste and low utilization rate in the allocation of resources of ideological and political education in colleges and universities. It is necessary to understand the ways and principles of the allocation of educational resources, as well as the allocation of political and educational resources for students in colleges and universities at the present stage, so as to promote the balance and rationalization of the allocation of political education resources. This paper constructs a university student political education resource allocation evaluation system, which can scientifically and objectively reflect the situation of the allocation of political education resources for college students in China. This paper puts forward and establishes a system model of the allocation and evaluation of college students' political education resources based on BP neural network, and carries out a simulation study. It proves that the network method applied to the evaluation of university students' political education resources allocation is feasible and operable.

\section{References}

[1]. Christodoulou G, Sgouritsa A, Tang B. On the Efficiency of the Proportional Allocation Mechanism for Divisible Resources. Theory of Computing Systems, 2016, 9347(4), pp. 1-19.

[2]. Wang Q, Ye B, Xu T, et al. Approximately Truthful Mechanisms for Radio Spectrum Allocation. IEEE Transactions on Vehicular Technology, 2015, 64(6), pp.2615-2626.

[3]. Hill N L. FFFR-Based Resource Allocation Mechanism for Interference Mitigation of D2D Communications in LTE-Advanced Networks. Canadian Medical Association Journal, 2015, 4(1), pp. 5-10. 
[4]. Wang L, Liu M, Meng Q H. A Hierarchical Auction-Based Mechanism for Real-Time Resource Allocation in Cloud Robotic Systems. IEEE Transactions on Cybernetics, 2016, pp.1-12.

[5]. Mashayekhy L, Nejad M M, Grosu D, et al. An Online Mechanism for Resource Allocation and Pricing in Clouds. IEEE Transactions on Computers, 2016, 65(4), pp. 1172-1184.

[6]. Santos A, Anta A F, Cuesta J A, et al. Fair linking mechanisms for resource allocation with correlated player types. Computing, 2016, 98(8), pp. 777-801.

[7]. Huang J, Xing C C, Qian Y, et al. Resource Allocation for Multi-cell Device-to-Device Communications Underlaying 5G Networks: A Game-Theoretic Mechanism with Incomplete Information. IEEE Transactions on Vehicular Technology, 2017, pp. 1-1.

[8]. Kou Y, Liu S, Zhang W, et al. Capacity allocation mechanism based on differentiated QoS in $60 \mathrm{GHz}$ radio-over-fiber local access network. Optics Communications, 2017, 387, pp. 290-295. 